\title{
SANTIAGO CALATRAVA: CONCILIAÇÃO HARMÔNICA ENTRE ARQUITETURA E ENGENHARIA
}

Korina Costa1; Mariana Demattei²; Leila Domingues²; Juliana Ganzela²; Jayne Moura²; Ivor Valeta²; Leandro Santos,.

Universidade do Oeste Paulista - UNOESTE, Faculdade de Engenharias e Arquitetura e Urbanismo, Presidente Prudente, SP.

\section{RESUMO}

O presente artigo constitui uma pesquisa qualitativa, do tipo revisão bibliográfica que analisa vida e obra de Santiago Pevsner Calatrava Valls, sendo de principal análise a obra Hemisferic na Cidade das Artes e Ciências em Valência, relacionando características relevantes do arquiteto e de seu período arquitetônico. Calatrava revela em suas obras a busca por uma arquitetura livre e complexa, que desperta o olhar do transeunte, que explora a escala de um edifício sublime e de alto desenvolvimento tecnológico. Em meio a diversas críticas, Calatrava mostra sua capacidade de surpreender através da conciliação da engenharia com a arquitetura, explorando em suas obras uma forma plástica com tendência orgânica, fazendo delas grandes expoentes da arquitetura contemporânea.

Palavras - chave: Calatrava, Valência, Hemisferic, forma de olho, arquitetura e engenharia

\section{SANTIAGO CALATRAVA: HARMONIC CONCILIATION BETWEEN ARCHITECTURE AND ENGINEERING}

\begin{abstract}
This paper is a qualitative research, type literature review that examines the life and work of Santiago Pevsner Calatrava Valls, being the main analysis the Hemisferic building in the City of Arts and Science in Valencia, revealing relevant characteristics of the architect and its architectural period. Calatrava reveals in his buildings the quest for a free and complex architecture, which awakens the gaze of passersby, which explores the scale of a sublime building and high technology development. Amid mixed reviews, Calatrava shows his ability to surprise through conciliation between engineering with architecture, exploring in their works a plastic form with organic trend, making them great exponents of contemporary architecture.
\end{abstract}

Keywords: Calatrava, Valencia, Hemisferic, eye form, architecture and engineering 


\section{INTRODUÇÃO}

A arquitetura contemporânea representa a quebra de todas as barreiras, sendo livre e extremamente complexa, no quesito onde o arquiteto possui uma liberdade que é expressa ou expressada na individualidade do criador, distanciando-se dos preceitos de normativas e da repetição de elementos, como era comum durante o período de apogeu do Movimento Moderno. Sendo assim, a contemporaneidade reforça a relação das necessidades sociais, econômicas e estéticas de um novo século, sendo atribuídas à razão e emoção. Podemos caracterizá-la como o equilíbrio harmônico físico-espacial do racional com a sensibilidade. (FRACALOSSI, 2013)

Com um vasto grupo de obras internacionais e edifícios que louvam uma devoção obstinada pela forma, o arquiteto e engenheiro espanhol Santiago Pevsner Calatrava Valls atravessa regularmente as linhas entre arte, arquitetura e engenharia. Ele nasceu em Valência, na Espanha no ano de 1951, o jovem espanhol já tinha ali seus primeiros contatos com a arte na escola de Artes e Ofícios, onde também em Valência, graduou-se no curso de Arquitetura na Escola Técnica Superior de Arquitetura e fez cursos de pós-graduação em urbanismo e graduado em engenharia civil. Continuou seus estudos como PhD de ciências técnicas do instituto de tecnologia federal suíço, e o doutorado honorário das universidades: Politécnica de Valença, universidade de Sevilha, universidade de Heriot-Watt em Edimburgo, na Escócia, e da escola de engenharia de Milwaukee. (ROSENFIELD, 2013)

No início de sua carreira, Calatrava trabalhou como engenheiro e começou a entrar em concursos de arquitetura. Seu primeiro projeto vencedor foi a concepção e construção de Estação Ferroviária Stadelhofen em Zurique, em 1983. No ano seguinte, Calatrava projetou e construiu uma ponte para os Jogos Olímpicos de Barcelona; este foi o início de uma série de projetos que estabeleceu a sua reputação internacional. (PORTAL METALICA, Disponível em http://wwwo.metalica.com.br/lyon-satolas-railway-station).

Considerado um engenheiro de esplêndidas qualificações, realizando obras que demonstravam leveza e todo seu domínio sobre a ciência. Em Zurique, se destacou com projetos de seu primeiro escritório, mas foi na Espanha e Suíça que se tornou especialista em pontes, por volta de 1990, onde se firmou a reputação de um grande engenheiro. (RATTENBURY, 2007)

\section{METODOLOGIA}

A presente pesquisa tomou como referência as pontuações e direcionamentos de Teixeira (2000), que define as etapas da pesquisa qualitativa, sendo assim, o presente trabalho se deu através de uma pesquisa dentre os teóricos sobre a tectônica e discussões em relação às arquiteturas cujo foco se dá através da poética da estrutura, seguido de uma pesquisa sobre o arquiteto Santiago Calatrava, seu método projetual e análise de como tal método e valorização do elemento estrutural se concretizam na obra em estudo, resultado este que é pertinente à maneira própria do pesquisador em se aproximar do objeto de pesquisa e de relacionar a teoria a tal realidade.

\section{UMA DISCUSSÃO SOBRE AS OBRAS DE CALATRAVA}

Calatrava é conhecido por seus edifícios flutuantes e curvos, para os quais utiliza materiais como o aço, concreto e novo modelo de computador para criar composições que aparecem ao mesmo tempo natural e estruturalmente impossíveis. Seus desenhos estilizados sugerem objetos, ondas naturais, asas, ou esqueletos branqueados de sol, com filas de nervuras de betão branco curvos em arcos parabólicos distorcidos, são concomitantemente delicados e de grande alcance. $O$ verdadeiro objetivo destes contornos dramáticos é tipicamente mais estético do que estrutural. (JODIDIO, 2012)

Seus projetos se destacam pela aparente complexidade. A estranheza formal nasce do empenho em evitar as soluções simplistas e os objetivos conhecidos para aceitar o desafio de 
confrontar questões econômicas, sociais e culturais. Com tais objetivos em mente, Calatrava empenha-se em unir estrutura e movimento. Uma das metas alcançadas por Calatrava na tarefa de criar uma poética do movimento consiste em incorporar-lhe aspectos sociais e culturais. Isso se deve a sua habilidade de deslocar-se entre arte, engenharia e arquitetura. (JODIDIO, 2012)

Apesar de todo esse caráter formal que envolve Calatrava, sua maior influência da engenharia foi o rigor geométrico de prédios históricos "a linguagem da geometria é tão importante quanto a linguagem da estrutura". Possui um traço sensual, que trabalha paralelamente ao high-tech projetando conjuntos quase que expressionistas, que abusavam do uso de novas tecnologias e materiais industriais. (REVISTA AU, 2002)

É possível identificar na obra de Calatrava a influência de outros arquitetos como as formas orgânicas de Gaudí e Joseph Paxton, o desenho aerodinâmico norte-americano da década de 50 e a expressividade escultórica de arquitetos do pós-guerra como Félix Candela, Kenzo Tange e Jorn Utzon. A arquitetura de Calatrava não se caracteriza exatamente como uma nova corrente, mas é possível ver uma semelhança também com arquitetos como Frank Gehry e Rem Koolhaas, isso pela exploração das tecnologias construtivas para edificar prédios em formatos ousados, desafiando as leis da natureza e promovendo uma transformação radical no cenário. (FERNANDES, 2011)

A obra de Calatrava chama a atenção por sua vivacidade, porém, tal esplendor também trouxe ao arquiteto diversas críticas e polêmicas, principalmente quanto aos gastos, havendo enorme diferença entre o orçamento e o custo final, além de questões funcionais, de conforto e segurança. (FRANCO, 2013)

A cidade natal do arquiteto, Valência, é palco de diversas obras e junto com elas cheia de polêmicas. Entre elas, o complexo Cidade das Artes e Ciências, foco do presente estudo. $O$ custo da mesma foi três vezes maior, uma casa de óperas que possui vista obstruída em 150 lugares, além de obras sem acessibilidade e equipamentos de segurança contra incêndio e saídas de emergência. (FRANCO, 2013).

Vale destacar que a arquitetura inovadora e extremamente exploratória das novas possibilidade tecnológicas acaba por promover atrasos na execução e constantes aumento dos custos, tornando assim, a sua produção um alvo de críticas, sendo difícil encontrar um projeto de Calatrava que não tenha custado muito mais que seu orçamento inicial. Há também queixas de que ele é indiferente às necessidades específicas de seus clientes, colocando o elemento escultórico e formal acima de outros condicionantes.

Tal contexto acarreta uma coleção de processos na justiça, dentre eles, destaca-se a ponte de pedestres em Veneza feita de vidro na qual mais de 50 pessoas sofreram fraturas após quedas e uma vinícola que possui vazamentos que prejudicam o controle de umidade, algo vital para a qualidade e conservação do vinho. Outro exemplo é o aeroporto em Bilbao, que foi executado sem terminal de desembarque e sem isolamento com a área externa diretamente para a calçada, fazendo então os passageiros esperarem no frio. "O problema é que Calatrava está acima do cliente". (MERINO apud FRANCO, 2013)

\section{RESULTADO DA ANÁLISE}

Construído sobre o leito de um rio transposto, a Cidade das Artes e das Ciências, é um complexo urbanístico e arquitetônico destinado ao entretenimento e à cultura com sete edifícios: Palau De Les Arts Reina Sofia, L' Umbracle, Museu Das Ciências Príncipe Felipe, L' Oceanographic, El Puente De L'assut De L'or, L'Àgora e L'Hemisfèric, o projeto da maioria deles foi de autoria de Calatrava, natural de Valência e que já gozava de prestígio internacional na época. A primeira construção do complexo foi o Hemisfèric, obra em estudo, inaugurada em 1998, mas boa parte do projeto foi concluída no século XXI. A Cidade tornou-se o destino de visitantes do mundo inteiro graças à concentração de atrações culturais e também pela obra em si. (MANOSSO, 2011) 
$\mathrm{Na}$ Cidade das Artes suas obras brancas se integram ao azul intenso do céu de Valência. A estrutura dos edifícios fica exposta, sendo ela algo fundamental para seu projeto estético. Os edifícios apresentam formas estranhamente orgânicas como um olho, uma baleia, uma ossada, uma concha, deixando as construções de aço, concreto e vidro da Cidade surpreendente.

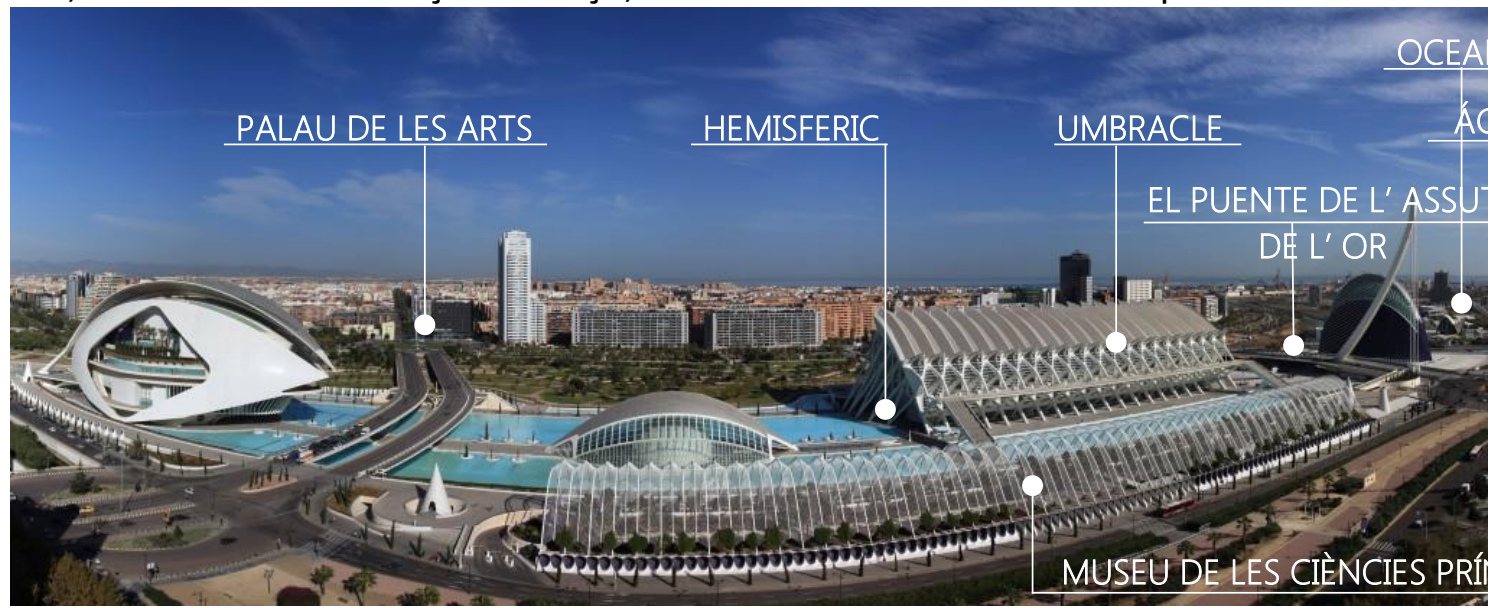

Figura 01. Complexo Cidade das Artes e Ciências

Fonte: Ciudad de las Artes y las Ciencias (2015)

Os prédios de Calatrava podem ser criticados como extravagantes e pouco funcionais, podem acusá-lo de não aproveitar bem os espaços, mas certamente ninguém há de ficar indiferente à criatividade das suas formas ousadas. (MANOSSO, 2011)

Dentre os edifícios do complexo arquitetônico, a pesquisa terá um olhar mais atencioso para a obra Hemisfèric, que é um planetário e um Cinema IMAX Dome, localizado na Cidade das Artes e das Ciências é o maior complexo de difusão cientifica e cultural na Europa. Ocupando uma área de $200 \times 1300 \mathrm{~m}$ numa área aproximada $26000 \mathrm{~m}^{2}$. A obra se limita entre duas piscinas retangulares, uma no norte e outra ao sul. A obra é um dos edifícios fundamentais do complexo, sendo o primeiro a ser inaugurado, construído de 1990 a 1998.

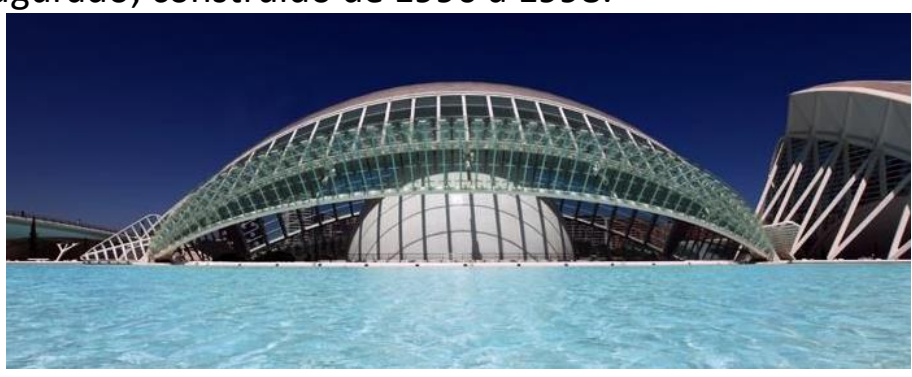

Figura 02. Obra em estudo L' Hemisfèric

Fonte: Ciudad de las Artes y las Ciencias (2015)

\section{ESTUDO DA FUNÇÃO}

Hemisfèric é a maior sala de projeção da Espanha, com três sistemas de projeção e uma tela côncava de $900 \mathrm{~m}^{2}$, filmes no formato IMAX Dome, cinema 3D e projeção digital para exibições astronômicas e demais espetáculos de entretenimento.

Tem capacidade para 306 espectadores, com uma das melhores estruturas e suportes técnicos do mundo, proporcionando aos visitantes as mais inovadoras sensações audiovisuais. A obra é composta por três corpos diferenciados, no lado leste há a cafeteria, lojas e escritórios. No centro há a sala de projeções e à oeste ficam os serviços técnicos. (FERNANDES, 2011)

\section{ESTUDO DA FORMA}

Lembrado pelo estudo da geometria em sua arquitetura e fascinado pela arquitetura modular e orgânica, Calatrava afirma que não busca ser entendido, busca ser livre. O Hemisferic é 
nitidamente inspirado no olho humano, cada uma de suas formas se encaixa cuidadosamente em sua estrutura, o planetário é representado pela pupila, o grande sobressalto são as pálpebras, e uma estrutura móvel que funciona como proteção, imita o abre e fecha semelhante ao olho humano. (FERNANDES, 2011)

O grande espelho d'agua que circunda todo o prédio se torna apenas mais uma vantagem, o olho se reflete, promovendo sua continuação tornando-o ainda mais exuberante.

Se tratando das faixadas menores de acessos nas extremidades, ao observá-las imediatamente sugerem o formato de um animal parecido com uma tartaruga, também é fato notar os formatos geométricos, como círculos, elipses, triângulos e trapézios. Calatrava não se preocupa em esconder seus métodos projetuais, sua admiração pela geometria e por elementos da natureza são combinados em suas obras, assim como esta. (MANOSSO, 2011)

\section{ESTUDO DA ESTRUTURA}

O Hemisferic tem como material predominante o concreto armado, a fundação do edifício junto aos muros de contenção, lajes, e arquibancadas somam $14.000 \mathrm{~m}^{3}$ para uma maior segurança e estabilidade é utilizado muros de arrimo perimetrais. A laje da fundação ancorada aos muros de arrimo tem de 1,50 a 2,00m de espessura. (FERNANDES, 2011)

A cúpula é composta por vigas metálicas de $90 \mathrm{~m}$, surgindo do nível da água e envolvendo a esfera com movimentos obtidos por meio de sistema hidráulico como se fossem as pálpebras do olho humano. Essa cúpula de formato ovoidal protege uma esfera em seu interior, sendo revestida por "trencadís" que são azulejos fragmentados, típico das cúpulas mediterrâneas, as janelas envidraçadas são de vidro laminado, a caixilharia de aço inoxidável, e na cobertura foram utilizados painéis de $40 \mathrm{~mm}$ de espessura de chapa metálica parafusadas à estrutura.

A esfera do planetário é feita de concreto, projetado em estrutura metálica formada por armaduras a base de perfis laminados. O concreto é quem dá rigidez à estrutura.

Os materiais de revestimento são usados para buscar um equilíbrio entre as superfícies de concreto e uso de edifício, piso em granito com diferentes formas e tratamentos e tapetes nas paredes da sala são técnicas adotadas no seu interior. No conjunto arquitetônico se destacam os elementos laterais móveis que funcionam como brises, a lateral transparente envidraçada, e o acabamento de "trencadís" de cor branco brilhante.

Essa estrutura singular da Hemisféric possibilitou tamanha dimensão do edifício sem prejudicar seu desempenho, cumprindo com o projeto estético e respondendo ao conceito da obra; Calatrava explorou da melhor maneira toda a tecnologia que a engenharia possibilita, tornando possível a significância do edifício com o movimento que é capaz de produzir, evidenciando o mesmo movimento que o olho humano realiza, causando o efeito "o olho que tudo se vê".

\section{CONCLUSÃO}

Calatrava, assim como outros arquitetos de seu período, busca seu estilo pessoal onde sua genialidade na engenharia possibilitou ainda mais o arquiteto conseguir atingir tão admiradas formas, obtendo resultados fascinantes com alta tecnologia e precisão de detalhes. A constante obsessão por mesclar estrutura e movimento, desafiar a ortogoniladade e a utilização de traços curvos, demonstra que Calatrava não possuía um padrão e sim, a vontade de inovar a cada projeto.

Seu desempenho em projetos formalistas causou críticas na mesma proporção sobre atrasos e custos das obras, mas no final o que fica é o fascínio que a obra traz, fazendo-se pertencer àquele lugar e valorizando-o, se tornando ponto turístico para os admiradores da arquitetura. As obras analisadas da Cidade de Artes e Ciência de Valência são exemplos disso, 
expõe a exuberância estética e alto conhecimento tecnológico, sendo possível abrigar diversas funções e ser a própria exposição.

O aspecto tectônico é visto em grande parte das obras de Calatrava, assim como acontece na Hemisfèric que revela originalidade e qualidade plástica em toda sua estrutura formalizando sua essência. A forma com que foi concedida, a engenhosa estrutura, e a função que abriga, estabelecem a mais completa harmonia, exibindo ciência, conhecimento, e sendo dotada de tecnologia.

\section{REFERÊNCIAS}

BARRATO, Romullo. Museu do Amanhã. 2015. Disponível em < http://www.archdaily.com.br/br/768578/museu-do-amanha-projeto-de-santiago-calatrava-norio-esta-proximo-de-ser-concluido > Acesso em: 20 de novembro de 2015.

BENEVOLO, Leonardo. A arquitetura do novo milênio. São Paulo: Estação Liberdade, 2007

FERNANDES, Thiago. Obra arquitetônica do século XX - Hemisfèric. 2011. Disponível em: <http://issuu.com/thiagofernandes7/docs/hemisferic_valencia>. Acesso em: 19 nov 2015

FRACALOSSI, Igor. "Fundamentos da Arquitetura Contemporânea / SiegbertZanettini". 2013.ArchDaily Brasil. Disponível em:<http://www.archdaily.com.br/106915/fundamentos-daarquitetura-contemporanea-slash-siegbert-zanettini>.Acesso em: 21 nov 2015

FRANCO, José Tomás. "Santiago Calatrava coleciona fãs... e também críticas " [Santiago Calatrava recolecta seguidores... y también críticas].ArchDaily Brasil. (Trad. Gabriel Pedrotti). 2013. Disponível em: <http://www.archdaily.com.br/160859/santiago-calatrava-coleciona-fas-dot-dotdot-e-tambem-criticas> Acesso em: 15 nov 2015

JODIDIO, Philip. Biografias- Santiago Calatrava. 2012. Disponível em:<https://pmiltonarquitetura.wordpress.com/2012/08/04/biografias-santiago-calatrava/ > Acesso em: 19 de novembro de 2015.

MAM, 2015. Quadracci Pavilion.Disponível em < http://mam.org/info/details/quadracci.php > Acesso em : 20 de novembro de 2015.

MANOSSO, Radamés. Cidade das Artes e das Ciências de Valência. 2011. Disponível em: < http://radames.manosso.nom.br/arquitetura/culturais/cidade-das-artes-e-das-ciencias-deValencia/?occur=1\&cover=0\&album=14\&photo=116>. Acesso em: 19 nov 2015

METALICA, Portal. Santiago Calatrava. Disponível em http://wwwo.metalica.com.br/lyon-satolasrailway-station APUD TASCHEN, Revista. ContemporaryEuropeanArchitects, Vol.III

OLIVEIRA, Camila. Geometria Orgânica: Responsável por três dos cinco edifícios de um complexo cultural em Valência, Espanha, Calatrava manifesta sua obsessão pela forma e pela maleabilidade estrutural típicas de sua expressão arquitetônica. 2002. Revista AU. Edição 103. Disponível em: $<$ http://au.pini.com.br/arquitetura-urbanismo/103/o-museu-das-ciencias-e-o-teatro-hemisfericodois-edificios-38989-1.aspx>. Acesso em: 19 nov 2015

ROSENFIELD, Karissa. How Santiago Calatrava blurred the lines between architecture and engineering to make buildings move. 2013. Disponível em: < 
http://www.archdaily.com/321403/how-santiago-calatrava-blurred-the-lines-betweenarchitecture-and-engineering-to-make-buildings-move>. Acesso em: 21 nov 2015

TEIXEIRA, E. As três metodologias. 2a ed. São Paulo: Vozes, 2000.

WIKIARQUITECTURA, 2015. Ponte de Alamillo. Disponível em < http://pt.wikiarquitectura.com/index.php/Ponte_de_Alamillo> Acesso em 20 de novembro de 2015. 